\title{
Managerial control in system of budgeting
}

\author{
Nesterov V.N. \\ Kazan Federal University \\ Institute of Management, Economics and Finance \\ Kazan, Russia
}

\author{
Kozlova N.N. \\ Kazan Federal University \\ Institute of Management, Economics and Finance \\ Kazan, Russia
}

\begin{abstract}
In this article the content of managerial control in the system of budgeting as an important source of information for business management, evaluation of the work of responsible persons on achievement of the scheduled purposes is considered. The method of monitoring over budget implementation based on determination of deviations and detections of the reasons of its emergence is explained. The analysis of deviations is given in digital data, and methods of detection of influence of separate factors on the general expenses' deviation and its detailing by types of expenses, responsibility centers, variable and constant expenses are shown. The relevance of this article is that in the present there are essential questions of control and management of different types of activity of the enterprise by preparation of specific programs of actions. These programs are called the budget (estimate) where such indicators as the planned income size, expenses, investments that need to be attracted to achieve the goal of activity of the company and another are reflected. Questions of identification of the reasons of a deviation from the budget and control of its execution are relevant.
\end{abstract}

Keywords-budget, estimate, control, expenses, factors, accounting

\section{INTRODUCTION}

Strategic and operational management of the enterprise in the conditions of the market demands creation of the reliable internal detailed information base. Interaction of three basic elements becomes a basis of the information support organization process of internal management: account, planning and control.

In the foreign practice, such information is presented in the form of managerial control which purpose is to provide realization of strategic aims of the enterprise, sufficient profit for financing it development. Administrative control is means of short-term management, allowing one to carry out effectively economic activity [1].

In an enterprise management system in general, managerial control is a component of management accounting and has a wider concept than assessment of a measure of responsibility of the managing director and his results of work. It is necessary to understand that control is a possibility of possession of all situations for adoption of optimal administrative solutions on goals achievement. In this regard control is necessary not only for a higher administrative system, but also for the controlled object as a learning tool of the formation reasons of the received results, deviations from the planned purposes and an opportunity to make the effective and timely correcting actions [10].

Managerial control allows one to solve the following tasks:

- to investigate the reasons of deviations;

- to inform various levels of management;

- to develop and apply the necessary correcting actions;

- to estimate activity of the responsible for execution tasks set for it.

A well put system of managerial control has to include the following complex of actions recommended, for example, by the French book of accounts:

- establishment of a common system of aims for all persons, who are responsible for the accounting concept and management;

- creation of a precautionary control system which allows one to be responsible persons, being conformed with definite purposes, to predict consequences, considered decisions and to try to obtain the greatest efficiency of the resources use which are available at their disposal;

- comparison of the budgetary forecasts to actual data in the constant analysis of positive and negative deviations from the established indicators and corresponding regulation;

- use of these forecasts for correction of the initial purposes or the correcting impact on the applied means.

Drawing up the budget is a planning process, usually calculated for a year with breakdown on quarters. The budget is the action program for each manager, each level of management and means of interaction between various divisions of the enterprise.

As a basis of planning and control over the implementation of plans, it is necessary to have the actual information presented in the form of the accounting and not accounting documentations which is saved up at the enterprise and received from the outside [11].

Obtaining the actual information for control in the system of accounting represents reflection of deviations by synthetic and analytical accounts, the analysis of data on the deviations accumulating on these accounts with considerable extent of specification and the subsequent write-off of deviations of accounts in realization or results. Accounting of deviations by 
means of the corresponding accounts provides the means necessary for the organization of the effective control system of financial and economic activity of the enterprise, and for employees of management - information for assessment of their actions and, therefore, taking measures for adjustment of the received results. Reflection of deviations by business includes practices in the basic in Anglo-Saxon and French accounting systems.

The other way of obtaining the actual information for control presents reflection of deviations from the system of synthetic and analytical accounts, and in primary documentation and various accounting registers. This way has not been focused on the end results, i.e. deviations have not been written off for results, however it allows one to carry out the analysis of deviations and reasons of its formation [2].

Monitoring represents profound variance analysis between the actual data and norms (standards) or the budgetary (plan) indicators as carefully prepared budget is the best standard. Such analysis is often called monitoring of the budget. Comparing of the actual and budgetary results is a main factor of assessment of activities of each level of control and the manager. It facilitates a choice of decisions and timeliness of the adjusting actions. In this case the actual results shall settle down so that it could be compared to the budget [12].

The procedure of the analysis consists in detection of factors and its assessment, leading to deviations of the actual cost from set and to further expansion of the general deviation on more private, coming, whenever possible, to the effective conditions of production. Such sequence is (from the general to the particular) most acceptable as the reverse sequence has risks leading to loss of factors, links between it and not to offer a complete explanation of emergence of the general result as the amounts of private deviations.

Necessary analysis condition of deviations is establishment of norms (standards). Standards for the first time appeared in England and the USA where labor control was its first function. Gradually the scope of norms application is extended, having spreaded to direct variables and constant expenses. These standards began to be used for counting future expenses and for the determination of product norm price. [13]:

Now standards allow one to solve the following problems

1) to exercise production control, based on the analysis of deviations;

2) to establish the preliminary prices. It is especially important for release of a new product, determination of a level of its profitability;

3) to develop budgets (estimates). It is necessary for prediction of financing expenses, employment, determination of investments size;

4) to increase efficiency and to simplify calculation of expenses;

5) to improve statement of responsibility at various levels of management.
In the process of the analysis, there is a problem of the choice and development of norms (standards). The analysis of conditions of production has to precede development of standards. Let us distinguish the following types of standards: main, ideal, average or current.

Constant norms which remain invariable throughout the long periods concern to the main. Such norms allow one to compare data for a number of years. In quickly changing conditions, these norms become unacceptable; therefore they are used seldom.

Ideal norms can be considered as a goal in ideal conditions of managing. In practice ideal norms can be hardly achievable, but it can be useful, for example, for stimulation of workers or as a landmark at improvement of the enterprise. When using ideal norms all deviations are considered as adverse [7].

The average standard or the current norms consider real conditions of production. These norms consider possible breakage of cars, differences in qualification of workers, the changes in price and influence of other factors. The current norms are put into practice most often as its provide acceptable base of measurement of deviations. It is also used for planning as represent the purposes which must be reached. That norms were real, it must be exposed to revision, considering changes in price, working conditions; the accumulated experience since the beginning of release of a product, change of the product, etc.

Development of standards demands big preliminary work and its quantity depends on complexity of a product and the production. Establishment of standards is a technical task, which decision is based on detailed studying of labor operations on production.

\section{METHOD}

The norms established in value terms allow one to present them as multiplication of price and quantity. Each of these elements conforms to a certain standard and the actual size which are often called as factors or private deviations. For example, the general deviation on materials in this case can be presented as follows [3]:

$$
\begin{aligned}
& \mathrm{E}=\left(\mathrm{Q} f^{*} \mathrm{Pf}\right)-(\mathrm{Qn} * \mathrm{Pn}) \text { or } \\
& \mathrm{E}=(\mathrm{Pf}-\mathrm{Pn}) * \mathrm{Qf}+(\mathrm{Qf}-\mathrm{Qn}) * \mathrm{Pn} \text { or } \\
& \mathrm{E}=\Delta \mathrm{P} * \mathrm{Qf}+\Delta \mathrm{Q} * \mathrm{Pn}
\end{aligned}
$$

where $\Delta \mathrm{P}^{*} \mathrm{Qf}$ - a deviation from the change in price; $\Delta Q^{*} \mathrm{Pn}-$ a deviation from the change of quantity.

The deviation from the change of quantity is called still a deviation from the productivity when it concerns labor expenses.

The analysis technique of deviations includes several basic moments:

- the analysis serves for operational management of production; therefore, the analysis of deviations must be 
carried out daily, and only quantitative factors change generally, and the price changes less often; as a rule, influence of the change in price is considered monthly;

- deviations must be considered not by the example of separate products, and in a section of factors of production (material, work, energy, etc.);

- the analysis must be carried out at each level of management, i.e. the center of responsibility. The results, received on separate divisions, are then generalized in general at the enterprise.

The analysis and control of management cannot be content with assessment of deviations. It is necessary to explain the reasons of deviations for developing the correcting actions. At the same time, the reasons of deviations need to be differentiated on separate factors - on quantitative and valuable. Among the possible reasons of deviations by a quantitative factor there are: bad setup or breakage of the equipment; discrepancy of material quality, workers qualification to the carried-out operations; quality of stockpile management and supply; low-quality setting standards, etc. Deviations in use of materials, as a rule, are controlled by the foreman. It is important that deviations in use of materials and their reasons have been established as soon as possible to take the correcting actions.

The possible reasons of deviations at the prices of materials can be caused by unsatisfactory work of purchasing department, for example, as purchase of poor quality material. The change in price can be caused by change of a situation in the market of materials. Irrational use of materials can lead to urgent additional purchase of materials with the reduced payment term. The supplier can carry out additional loading and discharging and transportation by the special urgent order and therefore demand a higher price for materials.

When determining the reasons of deviations, it is necessary to allocate the reasons depending on work of firm and out of the sphere of it influence. The reasons depending on work of firm should be distributed on the centers of responsibility to have an opportunity of its effective control.

In difference from deviations in use of materials which are daily exposed, the deviations at the prices are, as a rule, controlled monthly. In practice, time of purchases and time of materials use frequently don't coincide: the materials, which were purchased in one period, are used in another. The problem is in defining when to reveal deviations. Two options of calculation of deviations at the price are possible:

1) the full sum of deviations is calculated for the price in that period in which material purchased;

2) deviations in the price are counted according to amount of the used materials and are reflected in reports in that period when material was used.

It is recommended to use the first option because it allows one to define a cumulative deviation during this period when it occurs. It allows one to make in due time administrative decisions on elimination of undesirable deviations.
Development of production conditions - the automation growth, improvement of preparation functions and control of production increases a part of constant expenses in the general costs of production. Therefore, control can't be limited only to identification and the analysis of deviations by a direct cost. It is necessary to add this method to exercise control of all expenses of production. Development of the budget (estimate) and control of its implementation allows one to solve this problem.

Development of the budget is carried out in the centers of responsibility and allows one to count preliminary expenses and serves as information for further control of production efficiency by means of comparison with the established data [5].

When developing the budget, it is necessary to share direct and indirect costs. A preliminary direct cost is established by determination of norms, increased by the price and quantity by different types of expenses: materials, work, packing, energy, etc.

Preliminary indirect expenses count proceeding from quantity of work units and expenses on various sections, which participate in production. On each section, it is necessary to predetermine:

- all expenses of section;

- work units by means of which its activity is measured;

- productivity estimated by a number of work units for ensuring production.

Preliminary definition of these three components in each center of responsibility represents the estimate (budget).

\section{RESULT}

Control of the budget represents an explanation of deviations at each center of responsibility between the budget and the actual indicators.

In the analysis, deviations are not limited only to comparison of the estimate to actual data as deviations can arise also due to change of the output. Therefore, these estimates have to be corrected by the actual output.

Example: The center of production - mechanical shop.

Work unit - machine-hour.

Productivity -2 products, $\mathrm{A}$ and $\mathrm{B}$.

The established budget per month is presented in table I [4].

TABLE I. The established budget per month

\begin{tabular}{|l|l|l|l|}
\hline Product & Quantity & $\begin{array}{l}\text { Norm of machine } \\
\text { hours for product }\end{array}$ & $\begin{array}{c}\text { Number of machine } \\
\text { hours for all output }\end{array}$ \\
\hline A & 250 & 2 & 500 \\
\hline B & 120 & 3 & 360 \\
\hline Total: & 370 & 5 & 860 \\
\hline
\end{tabular}

The results of analysis are presented in table II. 
TABLE II. The results of analysis

\begin{tabular}{|l|l|l|l|}
\hline \multicolumn{1}{|c|}{ Indicators } & Budget & Fact & Deviation \\
\hline 1. Number of machine hours & 860 & 950 & 90 \\
\hline 2. Value of machine hours & 50 & 52 & 2 \\
\hline 3. Total costs & 43000 & 49400 & 6400 \\
\hline
\end{tabular}

The general expenses are the result of two components: quantities of machine hours and its costs. Therefore, the general deviation on expenses can be subdivided into a deviation by quantity of machine hours and its costs.

The deviation by quantity of machine hours is called a deviation by productivity and is calculated by a formula [14].

The actual number of machine hours is the number of machine hours on the estimate $*$ Value of unit Cost mash-hour on the estimate:

$(950-860) \times 50=4500$ rub.

The deviation caused by change of machine hours cost is determined by a formula [15].

Cost of machine hours on the estimate - Actual cost of machine hours * Actual quantity of machine hours:

$(52-50) \times 950=1900$ rub.

Check: $4500+1900=6400$ rub.

Change of the work single units number, in turn, can influence a deviation in cost. The general expenses consist of constant and variable expenses. Value of constant expenses does not depend on waste machine hours.

We will assume that all expenses were subdivided into variables and constants in the ratio (tab. III) [6].

TABLE III. The ratio of all expenses

\begin{tabular}{|l|l|l|}
\hline \multicolumn{1}{|c|}{ Indicators } & Budget & Fact \\
\hline Fixed costs & 20000 & 19000 \\
\hline Variable costs & 30000 & 30400 \\
\hline Total: & 50000 & 49400 \\
\hline
\end{tabular}

In the estimate, there was productivity provided at the level of 1000 machine hours, and actually it made 950 machine hours. Therefore, constant expenses with the actual productivity made:

$20000 \times 950 / 1000=19000$ rub.

On the estimate, the cost of one machine hour on constant expenditures was:

$20000 / 1000=20$ rub.

The deviation from the estimate by the number of machine hours is:

$1000-950=50$ machine hours

Therefore, the deviation at cost made:

$50 \times 20=1000$ rub.
As constant expenses do not change with change of the number of work single units, the over expenditure will make $1000 \mathrm{rub}$. This deviation is caused by change of activities between the estimate and the actual results.

The result caused by change of activities in value of constant expenses should be excluded. It will give the chance to research the deviations caused by efficiency of its use.

For this purpose, let us enumerate the budget, considering the actual activities, separating costs of constants and variables. At the same time, constant expenses do not change, and variables are adjusted by the actual activities. Such estimate received the name "floating" or flexible (tab. IV) [8].

TABLE IV. Flexible budget

\begin{tabular}{|l|l|c|c|}
\hline \multicolumn{1}{|c|}{ Indicators } & Flexible budget & Fact & Deviation \\
\hline Fixed costs & 20000 & 19000 & -1000 \\
\hline Variable costs & $28500(30 \times 950)$ & 30400 & 1900 \\
\hline Total: & 48500 & 49400 & 900 \\
\hline
\end{tabular}

\section{CONCLUSION}

Thus, the deviation from the account of expenses using efficiency will make 900 rub. Results of the factorial analysis can be presented by figure 1 [9].

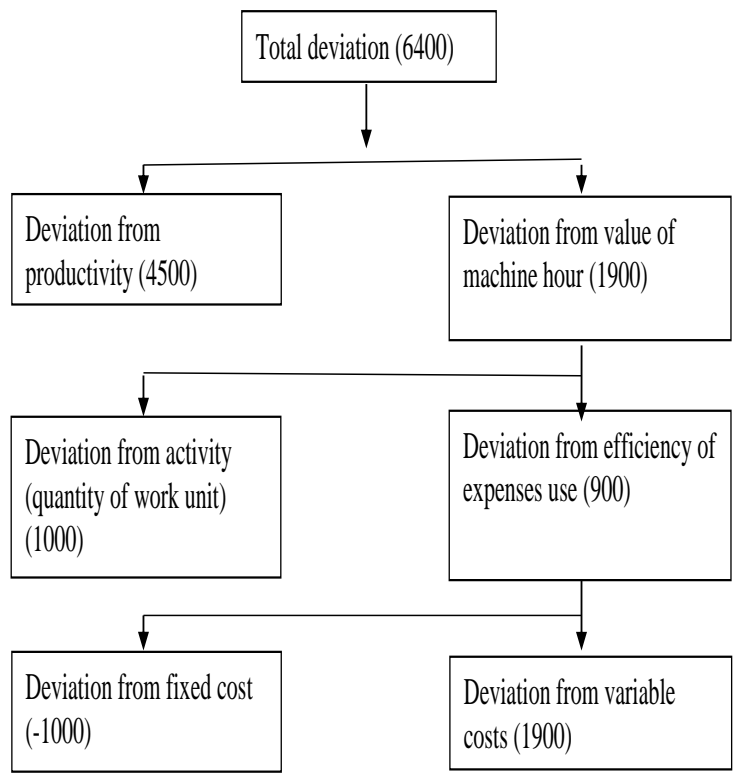

Fig. 1. Scheme of factors influence on general deviation by expenses

The analysis of the estimate allows one to define quantitative influence of factors on the general deviation and to make the relevant administrative decisions.

\section{References}

[1] Daniel Chiron, Comptabilite de 1 entreprise, Paris, 1985.

[2] Pierre Iasseque, Gestion de I entreprise et comptabilite, Paris, 1983 
[3] G.R. Faizrahmanova, N.N. Kozlova, The system of indicators of enterprises innovative activity, Asian Social Science, Vol.11, № 11, pp. 183-188.

[4] V.N. Nesterov, A.S. Akhtyamova, E.S. Domracheva, Accounting and analysis in managing the cost of innovation, Mediterranean Journal of Social Sciences, Vol. 6, Issue 1S3, 2015, pp. 217-221.

[5] A.N. Kirpikov, F.S. Nugaev, Relevant approaches to performing analysis of financial results of organization's activity with application of factor models, International Business Management, no. 10(15), 2016, pp. 2987-2991.

[6] A. Ferreira, D. Otley, The design and use of performance management systems: An extended framework for analysis, Management Accounting Research, Vol. 20, Issue 4, December 2009, pp. 263-282.

[7] T. Malm, D.A. Brownb, Management control systems as a packageOpportunities, challenges and research directions, Management Accounting Research, Vol. 19, Issue 4, December 2008, pp. 287-300.

[8] D. Otley, The contingency theory of management accounting and control: 1980-2014, Management Accounting Research, Vol. 31, June 2016, pp. 45-62.

[9] Lee D. Parker, Qualitative management accounting research: Assessing deliverables and relevance, Critical Perspectives On Accounting, Vol. 23, Issue 1 , January 2012, pp. 54-70.
[10] Robert Hchenhall, Management control systems design within its organizational context: findings from contingency-based research and directions for the future, Accounting, Organizations and Society, Vol. 8, Issues 2-3, February-April 2003, pp. 127-168.

[11] Jean Pascal Gond, Suzana Grubnic, Christian Herzig, Jeremy Moon. Configuring management control systems: Theorizing the integration of strategy and sustainability, Management Accounting Research, Vol. 23, Issue 3, September 2012, pp. 205-223.

[12] Diane Laure Arjaliès, Julia Mundy, The use of management control systems to manage CSR strategy: A levers of control perspective, Management Accounting Research, Vol. 24, Issue 4, December 2013, pp. 284-300.

[13] Kim Soin, Paul Collier, Risk and risk management in management accounting and control, Management Accounting Research, Vol. 24, Issue 2, June 2013, pp. 82-87.

[14] T.V. Elsukova, Lean accounting and throughput accounting: An integrated approach, Mediterranean Journal of Social Sciences, 2015, Vol.6, Is.3, pp. 83-87.

[15] A.Y. Sokolov, T.V. Elsukova, Using ABC to enhance throughput accounting: An integrated management approach, Academy of Strategic Management Journal, 2016, Vol.15, Special Issue 4, pp. 8-15. 